\title{
Biochemical origins of the non-monotonic receptor-mediated dose-response
}

\author{
M C Kohn and R L Melnick \\ Environmental Toxicology Program, National Institute of Environmental Health Sciences, PO Box 12233, MD A3-06, Research Triangle Park, \\ North Carolina 27709, USA \\ (Requests for offprints should be addressed to M C Kohn; Email: kohn@niehs.nih.gov)
}

\begin{abstract}
A mathematical model was created to examine how xenobiotic ligands that bind to nuclear receptor proteins may affect transcriptional activation of hormone-regulated genes. The model included binding of the natural ligand (e.g. hormone) and xenobiotic ligands to the receptor, binding of the liganded receptor to receptor-specific DNA response sequences, binding of co-activator or co-repressor proteins $(\mathrm{Rp})$ to the resulting complex, and the consequent transcriptional rate relative to that in the absence of the xenobiotic agent. The model predicted that the xenobiotic could act as a pure agonist, a pure antagonist, or a mixed agonist whose dose-response curve exhibits a local maximum. The response to the agent depends on the affinity of the liganded receptor-DNA complex for binding additional transcription factors (e.g. co-activator proteins). An inverted U-shaped dose-response occurred when basal levels of the natural ligand did not saturate receptor binding sites and the affinity for co-activator is weaker when the xenobiotic ligand is bound to the receptor than when the endogenous ligand is bound. The dose-response curve shape was not dependent on the affinity of the receptor for the xenobiotic agent; alteration of this value merely shifted the curve along the concentration axis. The amount of receptor, the density of DNA response sequences, and the affinity of the DNA-bound receptor for Rp determine the amplitude of the computed response with little overall change in curve shape. This model indicates that a non-monotonic dose-response is a plausible outcome for xenobiotic agents that activate nuclear receptors in the same manner as natural ligands.
\end{abstract}

Journal of Molecular Endocrinology (2002) 29, 113-123

\section{Introduction}

Nuclear receptors are protein transcription factors that become functionally active on binding of a ligand. When a liganded receptor binds to a particular DNA sequence (response element) near the promoter of a gene, it can modulate the rate of transcription of that gene. Current models of estrogen receptor-regulated transcription suggest that enhanced gene expression results from the recruitment by DNA-bound nuclear receptors of accessory proteins. These include co-activators or co-repressors that interact with the transcription initiation complex (Chen et al. 2000) or possess enzymatic activities (e.g. histone acetyltransferase, methyltransferase, ubiquitin ligase) that alter chromatin structure at the promoters of their target genes (Chen et al. 2000, McKenna \& O’Malley
2000). Dose-response profiles for receptormediated processes such as carcinogenesis can exhibit a variety of curve shapes (Hoel et al. 1983, Hoel \& Portier 1994), including rectangular hyperbolic, sigmoid, and U-shaped (either concave upward or convex upward). The molecular basis for nonlinear dose-response relationships has not been elucidated.

A U-shaped dose-response curve is nonmonotonic, i.e. it exhibits a change in the sign of its first derivative. This property can reflect either stimulatory or inhibitory dose-dependent effects on the biological response, according to the mechanistic role of the independent variable. Because current risk assessment procedures are based on the assumption that low-dose responses are linear or threshold appearing, the curve shape in the range of doses expected from environmental exposures 
to xenobiotic agents can have important consequences for estimates of the risk of adverse health effects consequent to such exposures.

Mathematical models that accurately represent regulation of biological systems can be used to predict the shape of dose-response curves at low doses. A hypothetical model of the receptormediated induction of a protein displayed qualitatively different dose-response behavior when numerical values of its parameters were altered (Kohn \& Portier 1993). Positive cooperativity in binding of ligand to the receptor resulted in sigmoid dose-response curves, and positive cooperativity in binding of the liganded receptor to an activating response element-produced U-shaped (concave upward) curves.

\section{Modeling methods}

In the present work, a simplified version of that early model (it lacks metabolism of the inducer, protein synthesis, and protein degradation) was constructed for xenobiotic ligands that bind to a nuclear receptor and activate transcription of genes normally regulated by the endogenous ligand. Features of this model are depicted in Fig. 1. Binding of the natural ligand (e.g. 17 $\beta$-estradiol, $\mathrm{E}_{2}$ ) to its receptor ('R' in Fig. 1) induces a conformational change that results in increased binding affinity of the receptor for co-activator proteins ('A'). The transcriptional rate of a reporter gene (luciferase under the control of an estrogen response element) transfected into $\mathrm{CV}-1$ cells was increased by about one order of magnitude when the cells were also transfected with the gene for the co-activator GRIP1 (Chen et al. 2000). Therefore, the transcription rate of the target gene in the present model was considered to be proportional to the concentration of DNA-bound liganded receptor that is also bound to co-activator protein.

Co-repressor proteins (Rp) may also bind to the liganded receptor but with different affinities from those of co-activator proteins. This simplified representation of the role of co-activators in mediating nuclear receptor function is intended to reflect the critical binding by the initial transcriptional factor that acts as a scaffold for the recruitment and assembly of the additional co-regulators that mediate expression of the target gene (Chen et al. 2000). In this model, if binding of the co-repressor out- competes binding of co-activator, the resulting complex is not transcriptionally active.

The xenobiotic ligand (' $\mathrm{X}$ ' in Fig. 1) also binds to the receptor but with lower affinity than the natural ligand. The conformational change induced by the xenobiotic ligand yields a structure with a lower binding affinity for co-activator protein than that of the natural ligand and, possibly, a higher affinity for Rp. Even in the presence of low concentrations of $\mathrm{X}$ (Fig. 1A), gene transcription is enhanced because the additional receptors bound with $\mathrm{X}$ and with co-activator proteins are transcriptionally active. At high concentrations of $\mathrm{X}$ (Fig. 1B), the number of receptors bound with the natural ligand is decreased due to the increased occupation of receptors by $\mathrm{X}$. As R•X binds co-activator more weakly than does $\mathrm{R} \bullet \mathrm{E}_{2}$, there may be less transcriptionally competent complex than in the absence of $\mathrm{X}$. This model was used to identify possible mechanistic requirements for the observation of inverted U-shaped (convex upward) dose-response curves.

The cellular concentrations of accessory proteins available to estrogen-responsive genes are unknown, so their actual binding affinities cannot be calculated. However, because the ratio of the binding constant to the accessory protein concentration appears in the differential equations that give the concentrations of the bound proteins needed to calculate the relative transcriptional rate (see below), the normalized non-dimensional value (e.g. $K_{\mathrm{D} \bullet \mathrm{R} \bullet \mathrm{x} \bullet \mathrm{A}}=K^{*} / \mathrm{A}$ ) can be used instead with no loss of generality. $\mathrm{EC}_{50}$ values for estrogen receptor-mediated gene expression have been determined for several xenoestrogens, permitting calculation of normalized binding constants for those agents. Some calculated values are $\mathrm{E}_{2}, 0 \cdot 45$ (Gaido et al. 1997); diethylstilbestrol (DES), 1·77 (Gaido et al. 1997); genistein 2.28 (Nikov et al. 2000); coumestrol, 2.08 (Nikov et al. 2000); nonylphenol, 1.64 (Laws et al. 2000); octylphenol, 2.20 (Sheeler et al. 2000); bisphenol A, 2117 (Gaido et al. 1997); methoxychlor, 18.5 (Gaido et al. 1997). No such data are available for $\mathrm{Rp}$, so the corresponding normalized binding constant was a free parameter in this model.

\section{Model structure}

The present model is based on Fig. 2. A receptor, ' $R$ ', was assumed to bind an endogenous ligand, $\mathrm{E}_{2}$ 
A

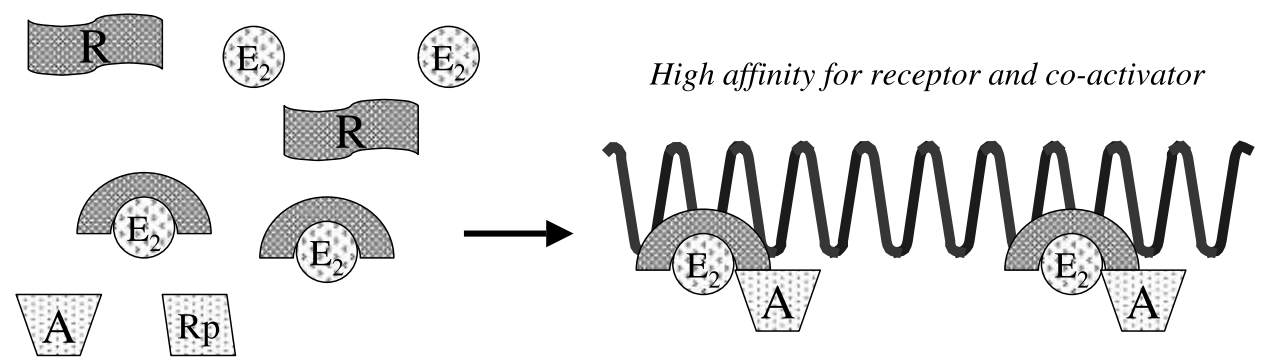

Low affinity for receptor and co-activator

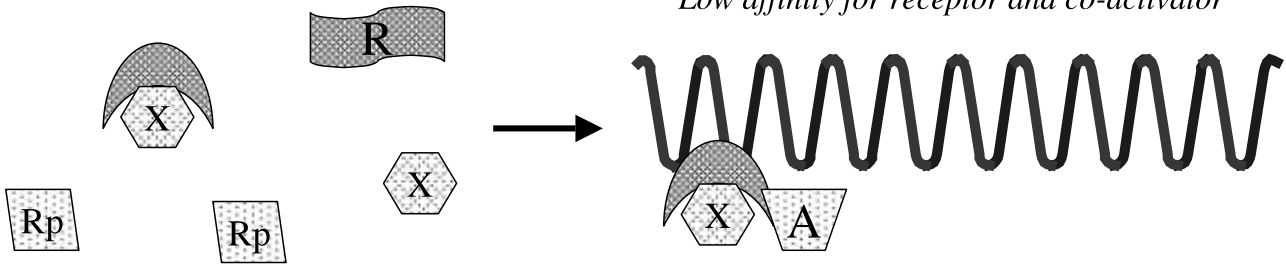

B
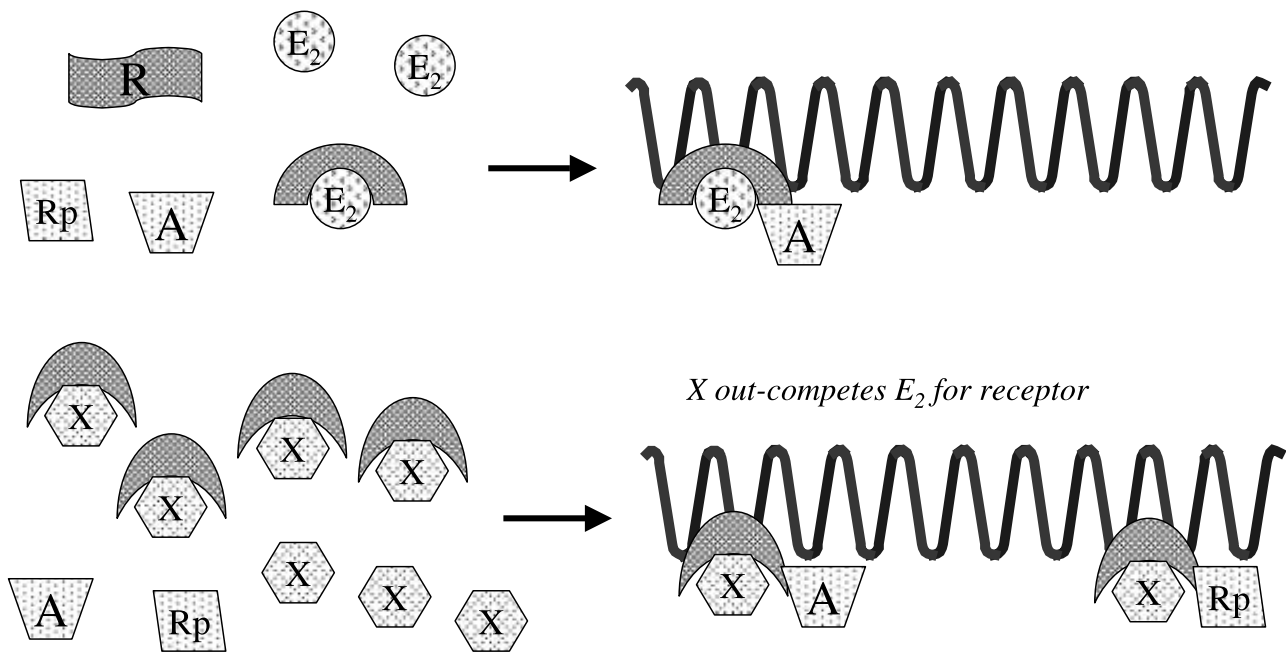

Figure 1 Schematic representation of the mechanism of expression of estrogen-dependent genes. Panel $A$, low concentration of xenobiotic ligand; panel $B$, high concentration of xenobiotic ligand. Symbols are $R=$ receptor, $E_{2}=17 \beta$-estradiol, $A=$ co-activator,

$\mathrm{Rp}=\mathrm{co}$-repressor, $\mathrm{X}=$ xenobiotic ligand. Note the conformational changes induced in the receptor consequent to ligand binding.

in this model, with a dissociation constant of $K_{\mathrm{R} \bullet \mathrm{E} 2}$ (a). The receptor also can bind a xenobiotic ligand, 'X', with a dissociation constant of $K_{\mathrm{R} \bullet \mathrm{X}}(\mathrm{b})$. The liganded receptors, $\mathrm{R} \bullet \mathrm{E}_{2}$ and $\mathrm{R} \bullet \mathrm{X}$, were assumed to bind to a DNA response element ('D') associated with a target gene with respective dissociation 


\section{Reference}

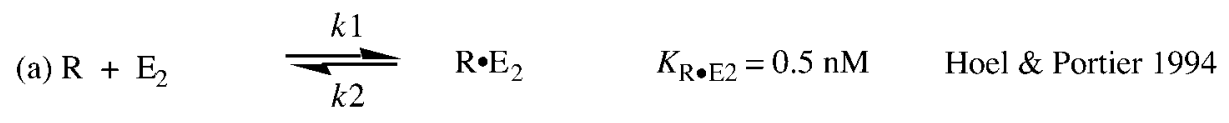
$k 3$

(b) $\mathrm{R}+\mathrm{X}$

$\underset{k 4}{\longrightarrow} \mathrm{R} \cdot \mathrm{X}$

$K_{\mathrm{R} \bullet \mathrm{X}}=1000 \mathrm{nM}$

Hoel \& Portier 1994, Laws et al 2000

(c) $R \cdot E_{2}+D$

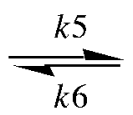

$\mathrm{D} \cdot \mathrm{R} \cdot \mathrm{E}_{2}$

$K_{\mathrm{RE} 2 \bullet \mathrm{D}}=1 \mathrm{nM}$

Lyttle et al 1992

(d) $R \cdot X+D$

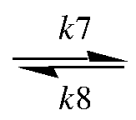

$\mathrm{D} \cdot \mathrm{R} \cdot \mathrm{X}$

$K_{\mathrm{RX} \bullet \mathrm{D}}=1 \mathrm{nM}$

Lyttle et al 1992

(e) $\mathrm{D} \cdot \mathrm{R} \cdot \mathrm{E}_{2}+\mathrm{A} \underset{k 10}{\stackrel{k 9}{\rightleftharpoons}}$

$\mathrm{D} \bullet \mathrm{R} \bullet \mathrm{E}_{2} \bullet \mathrm{A}$

$K_{\text {DRE2*A }}=0.5 \mathrm{nM}$

Furlow et al 1993, $M^{c}$ Kenna \& O'Malley 2000

(f) $\mathrm{D} \cdot \mathrm{R} \cdot \mathrm{X}+\mathrm{A} \quad \underset{k 12}{\stackrel{k 11}{\rightleftharpoons}}$

$\mathrm{D} \cdot \mathrm{R} \cdot \mathrm{X} \cdot \mathrm{A}$

$K_{\mathrm{DRX} \cdot \mathrm{A}}=1 \mathrm{nM}$

Murdoch \& Gorski 1991

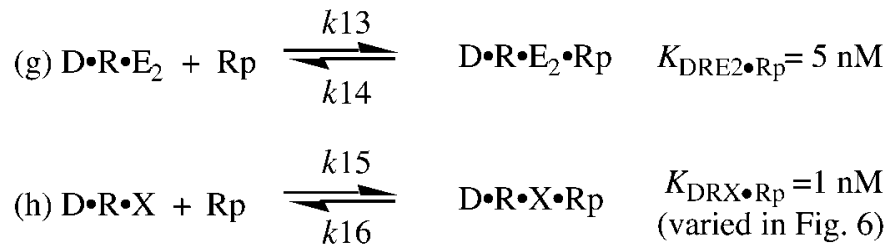

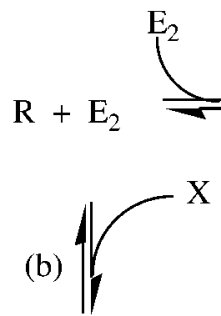<smiles>[R7]C=CC=C</smiles>

(c)
$\mathrm{D} \bullet \mathrm{R} \cdot \mathrm{E}_{2}$

(e)<smiles>C=CCCCCC</smiles>

$\mathrm{D} \cdot \mathrm{R} \cdot \mathrm{E}_{2} \bullet \mathrm{A}$

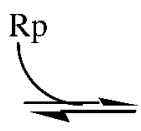

(g)

Assumed

\section{$\mathrm{D} \cdot \mathrm{R} \cdot \mathrm{E}_{2} \cdot \mathrm{Rp}$}

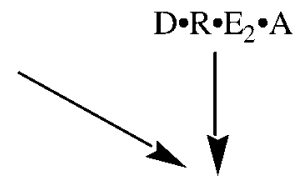

mRNA

(d)

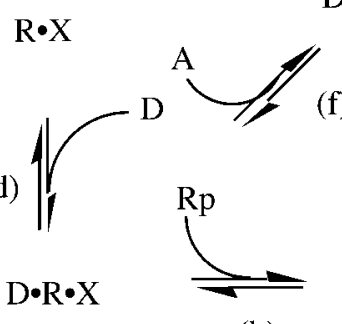

(f)

(h)

Figure 2 Ligand ( $E_{2}=$ endogenous estradiol, $\left.X=x e n o b i o t i c\right)$ binding to receptor (' $R$ ') and liganded receptor binding to DNA enhancer sequence ('D'). Accessory proteins that bind to the liganded receptor-DNA complex are $A=c o$-activator, $R p=$ co-repressor. The symbol at the end of each line is the dissociation constant for the complex being formed. 
constants of $K_{\mathrm{RE} \bullet \bullet \mathrm{D}}(\mathrm{c})$ and $K_{\mathrm{RX} \bullet \mathrm{D}}(\mathrm{d})$. The complex formed between the liganded receptor and response element may be stabilized by the binding of accessory protein(s), corresponding to $K_{\text {DRE2 } \bullet A}$ (e) and $K_{\text {DRX } \bullet A}(\mathrm{f})$ for binding of co-activator and $K_{\text {DRE2 } \bullet \text { Rp }}(\mathrm{g})$ and $K_{\text {DRX } \bullet \text { Rp }}(\mathrm{h})$ for binding of co-repressor respectively. When $\mathrm{X}$ is bound to $\mathrm{R}$, the activated receptor can bind to $\mathrm{D}$ and induce the same qualitative effects as those induced by $\mathrm{E}_{2}$. The net rate of transcription, hence the rate of expression of gene product, was assumed to be proportional to the total concentration of co-activator-bound complex $\left(\mathrm{D} \bullet \mathrm{R} \bullet \mathrm{E}_{2} \bullet \mathrm{A}+\right.$ $\mathrm{D} \bullet \mathrm{R} \bullet \mathrm{X} \bullet \mathrm{A})$.

All the equilibria in Fig. 2 occur simultaneously. Assembly of the transcriptional activation complex does not necessarily occur in the specified sequence. For example, a liganded receptor-coactivator complex may form prior to receptor binding to the response element (Margeat et al. 2001).

The eight mass action equations describing these simultaneous equilibria involve the calculation of 14 unknown concentrations and four unknown equilibrium constants. This is an unstable, underdetermined numerical problem, and no unique solution can be obtained. However, three unknown concentrations could be included in parameters for six equilibrium constants (only their ratios appear in the equations), thus reducing the number of unknowns but still leaving the problem underdetermined.

Each equilibrium process

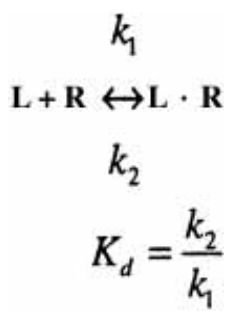

can be written as a set of differential equations given by the law of mass action, e.g.

$$
\begin{aligned}
& \frac{\mathrm{d}[\mathbf{L}]}{\mathrm{d} t}=-k_{1}[\mathbf{L}][\mathbf{R}]+k_{2}[\mathbf{L} \cdot \mathbf{R}] \\
& (\mathrm{L}=\text { estrogen receptor ligand })
\end{aligned}
$$

The differential equations corresponding to Fig. 2 are given in the Appendix.
Starting from arbitrary values for the concentrations, the differential equations can be integrated ( $t$, time, is in arbitrary units here) until a steady state is achieved and persists indefinitely. The actual numerical values of the rate constants are irrelevant. Because their ratios equal the equilibrium constants, the exact same solution will be achieved as it would if the eight nonlinear equations could be solved for the 14 unknown concentrations. The numerical values of the rate constants only affect the speed with which this equilibrium is attained. The terminal state will be exactly the one in which all the equilibria are simultaneously satisfied; forward and reverse rates for each reaction are exactly equal, keeping the concentrations of all chemical species constant indefinitely. Equilibrium was established before $t=2$, but the integration was carried to $t=10$ to ensure maintenance of the equilibrium.

The chemical equations were encoded in the SCoP language (Kohn et al. 1994) with parameter values comparable to those measured for the estrogen receptor. Estrogen receptor parameters were used in the model because of the greater availability of quantitative data reported for this receptor; however, the qualitative behavior of the model described here is not limited to estrogen receptor-mediated gene activation.

Although estrogen receptor dimerization is necessary for transcription (Wang et al. 1995, Margeat et al. 2001), the corresponding dissociation constant is small. Half maximal dimerization was observed at $0 \cdot 12 \mathrm{nM} \mathrm{E} \mathrm{E}_{2}$ (Sheeler et al. 2000), indicating that most of the liganded receptor would exist as dimers even at minimal levels of $\mathrm{E}_{2}$ in adult females. In addition, binding of the estrogen receptor to estrogen response elements (EREs) may (Boyer et al. 2000) or may not (Murdoch \& Gorski 1991) display cooperativity. Furthermore, there is evidence (Boyer et al. 2000) that estrogen receptors can bind to EREs as monomers and form dimers in situ. Therefore, a separate step for receptor dimerization would have no effect on the behavior of the model and was omitted from this simplified model.

Similarly, each receptor monomer in the dimer may be bound to $\mathrm{E}_{2}$ or $\mathrm{X}$. It is unknown how most xenoestrogens affect the binding constants for accessory proteins. If the affinity of a mixed dimer for accessory proteins were the average of the affinities of the homodimers, including dimeriz- 
ation would have no effect on the numerical output of the model.

The dissociation constants were set to $K_{\mathrm{R} \bullet \mathrm{E} 2}=0.5 \mathrm{nM}$ for $\mathrm{E}_{2}$ (Laws et al. 2000), $K_{\mathrm{R} \bullet \mathrm{x}}=1000 \mathrm{nM}$ (comparable to the values (Dodge et al. 1996, Laws et al. 2000) for several weakly estrogenic chemicals), and $K_{\mathrm{RE} \cdot \mathrm{D}}=K_{\mathrm{RX} \bullet \mathrm{D}}=1 \mathrm{nM}$ (Inano et al. 1994). The binding affinity of the estrogen receptor for EREs appears to be independent of the ligand bound to the receptor, and may occur in the absence of ligand (Curtis \& Korach 1991, Inano et al. 1994). As the intracellular concentrations of co-activators and co-repressors are unknown, these quantities were divided into their respective dissociation equilibrium constants, resulting in a dimensionless quantity. $K_{\text {DRE2 •A }}$ was fixed at $0 \cdot 5$ (Gaido et al. 1997, Suen et al. 1998, Thénot et al. 1999), and $K_{\mathrm{DRX} \bullet \mathrm{A}}$ is a parameter in the model. In the absence of data, $K_{\text {DRE2 } \bullet \text { Rp }}$ was fixed at 5 , and $K_{\text {DRX } \bullet \text { Rp }}$ is a parameter in the model, whose effect was studied by computer experiments in which its value was systematically varied.

The initial concentrations of $\mathrm{E}_{2}$ and $\mathrm{R}$ were respectively set to $0 \cdot 2 \mathrm{nM}$ (blood $\mathrm{E}_{2}$ concentration in female rats) and $10 \mathrm{nM}$ (Furlow et al. 1993). If $\mathrm{E}_{2}$ equilibrates between serum and tissue, use of the blood hormone level serves as the upper bound of tissue concentrations. The initial concentration of $\mathrm{E}_{2}$ relative to the concentration of $\mathrm{R}$ ensures that unoccupied receptors are present in excess over the endogenous ligand. The value for $\mathrm{D}$ is unknown. Therefore, it was set to 1 so that the solution of the equations corresponded to the fraction of $\mathrm{D}$ that is transcriptionally active.

Using the law of mass action, the above scheme was converted into differential equations. These equations were integrated with $\mathrm{SCoP}$ (Kootsey et al. 1986) from time $=0$ to time $=10$ for each of several initial concentrations of $\mathrm{X}$ to distribute ligand and receptor among their free and bound forms and to achieve the corresponding steady-state solutions. The steady-state value of

$$
\begin{aligned}
& v_{\text {relative transcripion }}= \\
& \frac{\left[\mathrm{D} \cdot \mathrm{R} \cdot \mathrm{E}_{2} \cdot \mathrm{A}\right](\mathrm{X})+[\mathrm{D} \cdot \mathrm{R} \cdot \mathrm{X} \cdot \mathrm{A}](\mathrm{X})}{\left[\mathrm{D} \cdot \mathrm{R} \cdot \mathrm{E}_{2} \cdot \mathrm{A}\right](\mathrm{X}=0)}
\end{aligned}
$$

gives the effect (relative to $\mathrm{X}=0$ ) of $\mathrm{X}$ on the expression rate of a gene regulated by $\mathrm{E}_{2}$.

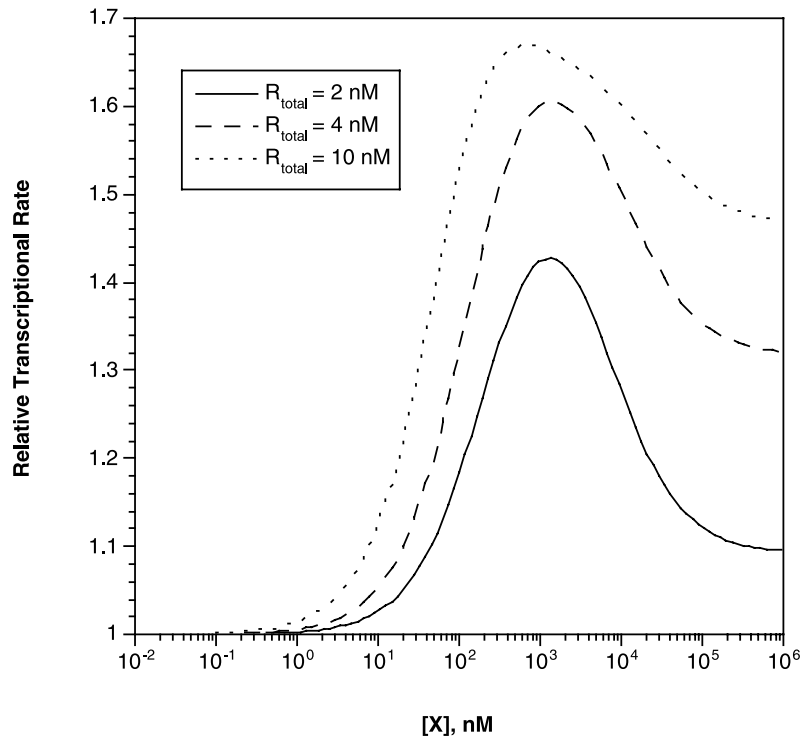

Figure 3 Effect of total amount of estrogen receptor on relative transcriptional rate. Other parameter values are as given in Fig. 2. Although the response is not directly proportional to receptor concentration because of saturation at lower receptor concentrations, the effect is mainly on the amplitude of the response and not on the curve shape.

Implicit in this formulation is the notion that the scaffold of proteins assembled on the response element has the same effectiveness at inducing transcription regardless of the receptor ligand that initiated the process. Each ligand alters the affinities of the bound receptor for accessory proteins to a different extent as shown by Kraichely et al. (2000).

\section{Results}

Receptor-mediated responses are routinely observed at ligand concentrations far below those that result in occupation of most of the receptor binding sites. Under most conditions response elements are occupied to a small extent, and saturation of the cellular response occurs at receptor titers far above those found naturally (Webb et al. 1992). This is the origin of the concept of 'spare receptors,' and is illustrated by the model's predictions in a computer experiment (Fig. 3).

The initial concentration of $\mathrm{R}$ was varied (Fig. 3, $\mathrm{R}=2,4$ or $10 \mathrm{nM}$ ). In each of these cases there were unoccupied ligand-binding sites $\left(E_{2}=0.2 \mathrm{nM}\right)$ 


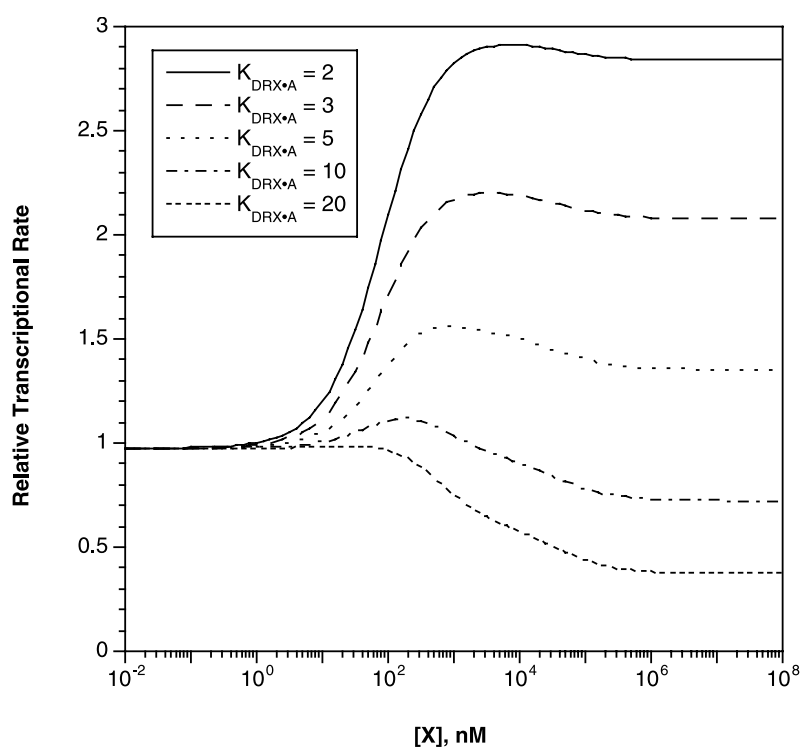

Figure 4 Dose-response profiles for relative transcriptional rate at different affinities $\left(K_{\mathrm{DRX} \cdot \mathrm{A}}\right)$ of the DNA-bound liganded receptor $(D \cdot R \cdot X)$ for the co-activator ('A'). The xenobiotic agent can act as a pure agonist, a pure antagonist, or a mixed agonist depending on the affinity. $K_{\mathrm{DRX} \cdot \mathrm{Rp}}=5$. Other parameter values are given in Fig. 2.

in the absence of $\mathrm{X}$. As a result, all three dose-response curves exhibit an inverted-U shape, and the maximal response was increased with increasing receptor concentration. Elimination of the inverted U-shaped dose-response curve was achieved by increasing the concentration of $\mathrm{E}_{2}$ to the point that all ligand-binding sites of $\mathrm{R}$ were bound with $\mathrm{E}_{2}$. With no unoccupied receptors, additional transcriptional activation was impossible and $\mathrm{X}$ was predicted to be a pure antagonist. As the total receptor concentration changes, the response changes in amplitude but not in curve shape. The response is not in direct proportion to receptor concentration because saturation of response elements occurs at normally available receptor concentrations. As the transcriptional rate is limited by availability of response elements, supplying additional receptors does not greatly increase the rate.

The model developed here produced an inverted U-shaped dose-response curve as the total tissue concentration of $\mathrm{X}$ increased from 1 to $10^{4} \mathrm{nM}$ (Fig. 4, especially curves with $\left.K_{\mathrm{DRX} \bullet \mathrm{A}}=5-10\right)$. This behavior requires unoccupied receptors in the presence of endogenous ligand $\mathrm{E}_{2}$, i.e. free

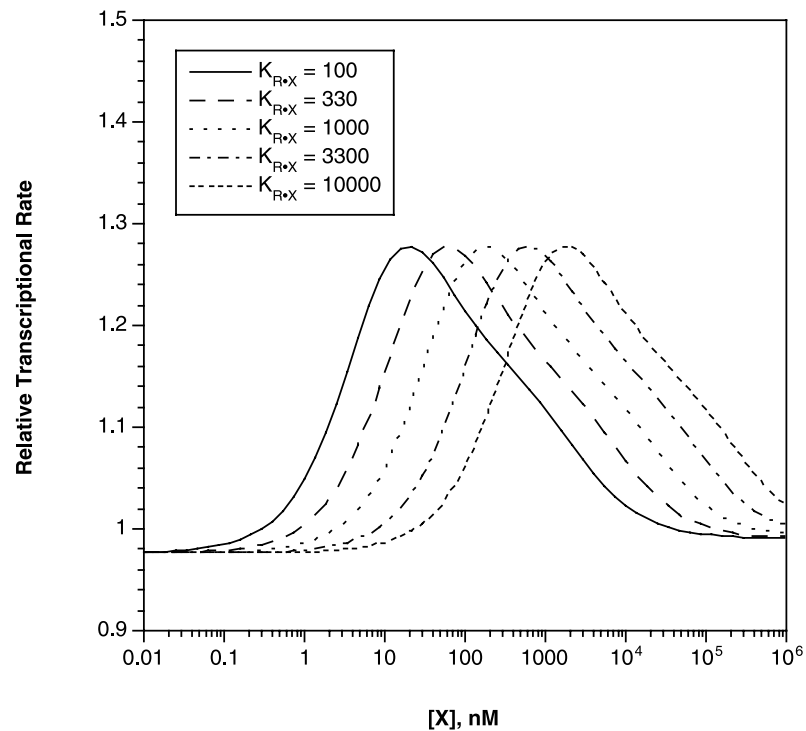

Figure 5 Altering the affinity of the receptor for the xenobiotic ligand (' $X$ ') does not affect the shape of the dose-response curve. It merely shifts the maximum of the curve to higher or lower concentrations. $K_{\mathrm{DRX} \cdot \mathrm{A}}=10$; $K_{\mathrm{DRX} \cdot \mathrm{RP}}=5$.

receptors are available at normal levels of endogenous hormone. At low concentrations of $\mathrm{X}$ (between 1 and $100 \mathrm{nM}$ ), some of the unoccupied receptors become liganded with $\mathrm{X}$, and expression of the responsive gene is predicted to increase. This is true even for xenoestrogens that have a weak affinity for R. In this model the binding affinity of $\mathrm{X}$ is 2000 times weaker than that of $\mathrm{E}_{2}$ for $\mathrm{R}$. At high concentrations of $\mathrm{X}$ (above $1000 \mathrm{nM}$ ), the xenoestrogen out-competes $\mathrm{E}_{2}$ for $\mathrm{D}$. Because $K_{\mathrm{DRX} \bullet \mathrm{A}}>>K_{\mathrm{DRE} 2 \bullet A}$, there is less liganded receptorDNA response element complexes bound with co-activator, and the net receptor-mediated effect is reduced. If $\mathrm{A}$ has a high affinity for the $\mathrm{D} \bullet \mathrm{R} \bullet \mathrm{X}$ complex, $\mathrm{X}$ behaves like a pure agonist (Fig. 4, $K_{\mathrm{DRX} \bullet \mathrm{A}}=2$ ). If $\mathrm{A}$ has a low affinity, such that Rp out-competes A for binding to the receptor-DNA complex, $\mathrm{X}$ behaves like a pure antagonist (Fig. 4, $\left.K_{\mathrm{DRX} \bullet \mathrm{A}}=20\right)$.

In contrast to changes in $K_{\mathrm{DRX} \bullet \mathrm{A}}$, changing $K_{\mathrm{R} \bullet \mathrm{X}}$ did not alter the shape of the dose-response curve (Fig. 5). Increasing $K_{\mathrm{R} \bullet \mathrm{x}}$ (decreasing the affinity of $\mathrm{X}$ for $\mathrm{R}$ ) shifts the curve to the right, whereas decreasing $K_{\mathrm{R} \bullet \mathrm{X}}$ (increasing the affinity of $\mathrm{X}$ for $\mathrm{R}$ ) shifts the curve to the left. Figure 5 represents responses that may be expected from xenoestrogens that differ only in their affinity for $\mathrm{R}$. 


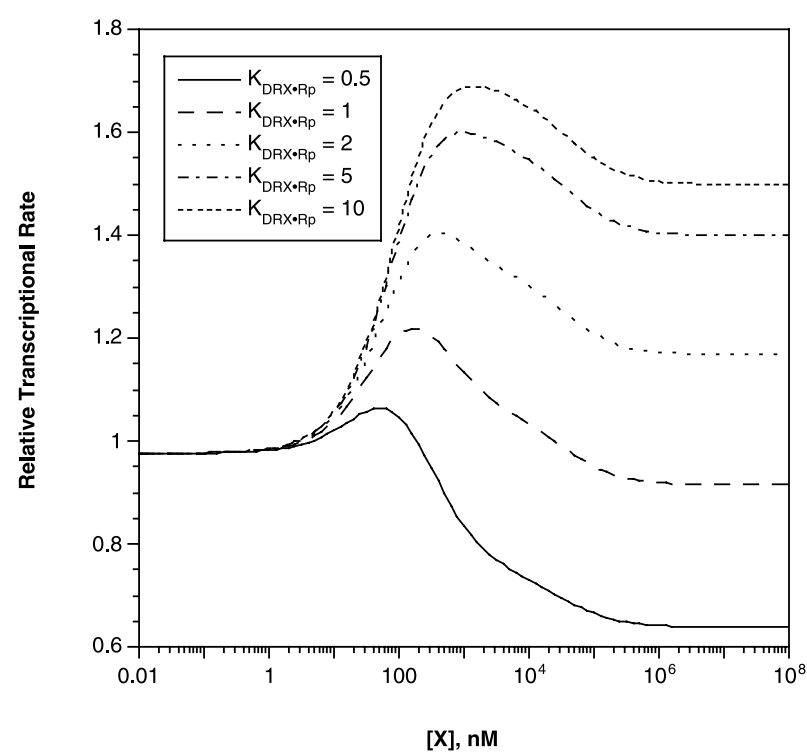

Figure 6 Influence of $K_{\mathrm{DRX} \text {.Rp }}$ on the dose-response curve shape. $K_{\mathrm{DRX} \cdot \mathrm{A}}=10 ; K_{\mathrm{R} \cdot \mathrm{X}}=1000$.

When the concentration of $\mathrm{D}$ (initially $=\ln \mathrm{M}$ ) was varied from 0.5 to 10 , it was still possible to identify parameter values that predicted $\mathrm{X}$ to be either a pure agonist or a pure antagonist or to produce an inverted U-shaped dose-response. The effect was merely to alter the amplitude of the response curve.

At high affinity for co-repressor (Fig. 6, $\left.K_{\text {DRX } \bullet \text { Rp }}=0 \cdot 5\right)$ the xenobiotic ligand acts mainly as an antagonist, and at low affinity (Fig. $6, K_{\text {DRX } \bullet \text { Rp }}=$ $10)$ it acts mainly as an agonist. However, this qualitative difference is largely due to alteration of the amplitude of the response. By competing with co-activator for binding to the $\mathrm{D} \bullet \mathrm{R}$ complex, the co-repressor reduces the amount of transcriptionally competent complex present, and thus the rate of transcription decreases.

\section{Discussion}

The present model predicts that inverted U-shaped responses to xenobiotic ligands of transcriptionally active receptors require the existence of unoccupied receptors that are available to bind with $\mathrm{X}$. Serum-free (not bound to steroid-binding globulin) $\mathrm{E}_{2}$ in normally cyclic women rises from $0 \cdot 16 \mathrm{nM}$ early in the follicular stage to $0 \cdot 44 \mathrm{nM}$ (maximal mean value reported is $0.8 \mathrm{nM}$ ) in mid-cycle (Sehested et al. 2000). As the estrogen receptor $K_{\mathrm{d}}$

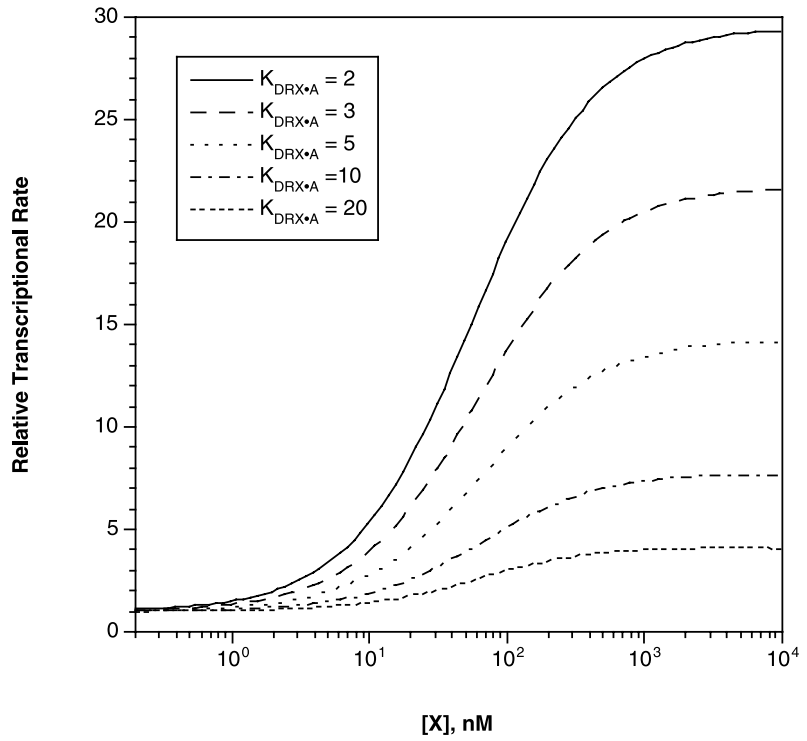

Figure 7 Effect of $K_{\mathrm{DRX}}$ on relative transcriptional rate when $\mathrm{E}_{2}=0.02 \mathrm{nM}$ (serum concentration in men and juveniles). At these low estradiol levels, there are so many unoccupied receptors that $\mathrm{X}$ acts as an agonist even when co-activator binding is weak $\left(K_{\mathrm{DRX} \cdot \mathrm{A}}=20\right)$. Other parameter values are given in Fig. 2.

for $\mathrm{E}_{2}$ is $0.5 \mathrm{nM}$, the receptor is unlikely to be saturated even at mid-cycle. For young girls, the existence of unoccupied receptors is even clearer. Circulating $\mathrm{E}_{2}$ in prepubescent girls has been measured (Ankarberg \& Norjavaara 1999) at $0 \cdot 01-0.02 \mathrm{nM}$, rising to $0 \cdot 1-0 \cdot 8 \mathrm{nM}$ at the end of puberty. As the maximal occupation of the receptor in the absence of cooperative binding of ligands (calculated from the Michaelis-Menten equation) is about $60 \%$, the existence of unoccupied receptors appears to be generally true.

Circulating $\mathrm{E}_{2}$ is also lower in men and boys. The model's predictions when $\mathrm{E}_{2}=0.02 \mathrm{nM}$ are given in Fig. 7. Even when co-activator binding is weak $\left(K_{\text {DRX } \bullet A}=20\right)$, the xenoestrogen acts as a pure agonist. This behavior is due to the existence of a large number of unoccupied receptors in the absence of $\mathrm{X}$ that is available for binding the xenoestrogen. At low $\mathrm{E}_{2}(0 \cdot 02 \mathrm{nM}$, Fig. 7) the absolute transcriptional rate is low in the absence of $\mathrm{X}$, and the relative rate increase in the presence of $\mathrm{X}$ is much larger than at high $\mathrm{E}_{2}(0 \cdot 2 \mathrm{nM}$, Fig. 4). Thus, men and prepubescent boys and girls may be more susceptible to the effects of xenoestrogens.

The model predicts that as $\mathrm{X}$ increases, the unoccupied receptors become liganded and the 
transcriptional signal increases beyond that resulting from the endogenous ligand alone. At high concentrations of $\mathrm{X}$, the xenobiotic agent will out-compete $\mathrm{E}_{2}$ for $\mathrm{R}$, and most of the receptor will be bound with $\mathrm{X}$. As the affinity of $\mathrm{D} \bullet \mathrm{R} \bullet \mathrm{X}$ for co-activator is lower than that of $\mathrm{D} \bullet \mathrm{R} \bullet \mathrm{E}_{2}$, the concentration of $\mathrm{D} \bullet \mathrm{R} \bullet \mathrm{E}_{2} \bullet \mathrm{A}$ will be lower than it would be in the absence of $\mathrm{X}$. Consequently the rate of expression will be lower.

This behavior was not qualitatively altered by changes in receptor concentration (as long as $\mathrm{R}$ exceeds $\mathrm{E}_{2}$ ), the affinity of the receptor for the xenobiotic ligand $\left(K_{\mathrm{R} \bullet \mathrm{X}}\right)$, or the concentration of response elements (as long as these elements are not saturated with receptor in the absence of xenobiotic ligand). When different $K_{\mathrm{R} \bullet \mathrm{x}}$ values representative of xenobiotic agents that activate R - DES, $0.2 \mathrm{nM}$; ethynylestradiol, $0.4 \mathrm{nM}$; nonylphenol, $672 \mathrm{nM}$; octylphenol, $781 \mathrm{nM}$; bisphenol A, $1.57 \mu \mathrm{M}$; methoxychlor, $65 \mu \mathrm{M}$ (Laws et al. 2000)were used in the model, the shape of the dose-response curve was not changed.

The primary effect of a change in $K_{\mathrm{R} \bullet \mathrm{x}}$ is a shift in the positions on the $\mathrm{X}$ concentration axis of the maximum of the dose-response curve. Similarly, variation in the affinity for co-repressor affected mainly the amplitude of the response rather than the qualitative effect of the xenobiotic ligand. Only the affinity of the enhancer-bound liganded receptor for co-activator $\left(K_{\text {DRX } \bullet A}\right)$ strongly affected the shape of the dose-response curve. If $K_{\mathrm{D} \bullet \mathrm{Rp}}$ is decreased (i.e. greater affinity for co-repressor), the xenoestrogen would appear primarily antagonistic.

Such a shift between agonistic and antagonistic behavior has been observed in yeast transfected with genes for estrogen receptor and a $\beta$-galactosidase gene under the control of an ERE. Thus, the alternative ligands ICI 164,384, ICI 182,780, and tamoxifen activate transcription at low doses but diminish transcription at high doses (Lyttle et al. 1992, Wang et al. 1995).

Although this model is extremely simple, the robustness of its predictions illustrates the plausibility of inverted U-shaped dose-response profiles for receptor-mediated processes. As $K_{\mathrm{DRX} \bullet \mathrm{A}}$ values are unknown for most xenobiotic agents that transcriptionally activate nuclear hormone receptors, this model has identified a critical research need. These results indicate that quantitative measurement of the mechanistic events involved in receptor-mediated responses, the concentrations of the various components of the system (e.g. $\mathrm{E}_{2}, \mathrm{X}$, $\mathrm{D}, \mathrm{A}, \mathrm{Rp}$ ), and the dissociation constants given in Fig. 2 are crucial to reliably predict effects from exposures to xenobiotic ligands that transcriptionally activate that receptor.

\section{References}

Ankarberg C \& Norjavaara E 1999 Diurnal rhythm of testosterone secretion before and throughout puberty in healthy girls: correlation with $17 \beta$-estradiol and dehydroepiandrosterone sulfate. Fournal of Clinical Endocrinology and Metabolism 84 975-984.

Boyer M, Poujol N, Margeat E \& Royer CA 2000 Quantitative characterization of the interaction between purified human estrogen receptor $\alpha$ and DNA using fluorescence anisotropy. Nucleic Acids Research 28 2494-2502.

Chen D, Huang S-M \& Stallcup MR 2000 Synergistic, p160 coactivator-dependent enhancement of estrogen receptor function by CARM1 and p300. Fournal of Biological Chemistry 275 $40810-40816$

Curtis SW \& Korach KS 1991 Uterine estrogen receptor-DNA complexes: effects of different ERE sequences, ligands, and receptor forms. Fournal of Molecular Endocrinology 5 959-966.

Dodge JA, Glasebrook AL, Mages DE, Phillips DL, Sato M, Short LL \& Bryant HU 1996 Environmental estrogens. Effects on cholesterol lowering and bone in the ovariectomized rat. Fournal of Steroid Biochemistry and Molecular Biology 59 155-161.

Furlow JD, Murdoch FE \& Gorski J 1993 High affinity binding of the estrogen receptor to a DNA response element does not require homodimer formation or estrogen. Fournal of Biological Chemistry 268 12519-12525.

Gaido KW, Leonard LS, Lovell S, Gould JC, Babai D, Portier CJ \& McDonnell DP 1997 Evaluation of chemicals with endocrine modulating activity in a yeast-based steroid hormone receptor gene transcription assay. Toxicology and Applied Pharmacology 143 205-212.

Hoel DG \& Portier CJ 1994 Nonlinearity of carcinogenesis doseresponse functions. Environmental Health Perspectives 102 (Suppl) $109-113$

Hoel DG, Kaplan NL \& Anderson MW 1983 Implication of nonlinear kinetics on risk estimation in carcinogenesis. Science $\mathbf{2 1 9}$ 1032-1037.

Inano K, Gurtis SW, Korach KS, Omata S \& Horigome T 1994 Heat shock protein 90 strongly stimulates the binding of purified estrogen receptor to its responsive element. Fournal of Biochemistry $116759-766$.

Kohn MC \& Portier CJ 1993 Effects of the mechanism of receptormediated gene expression on the shape of the dose-response curve. Risk Analysis 13 565-572.

Kohn MC, Hines ML, Kootsey JM \& Feezor MD 1994 A block organized model builder. Mathematical and Computer Modelling 19 75-97.

Kootsey JM, Kohn MC, Feezor MD, Mitchell GR \& Fletcher PR 1986 SCoP: an interactive simulation control program for microand minicomputers. Bulletin of Mathematical Biology 48 427-441.

Kraichely DM, Sun J, Katzenellenbogen JA \& Katzenellenbogen BS 2000 Conformational changes and coactivator recruitment by novel ligands for estrogen receptor- $\alpha$ and estrogen receptor- $\beta$ : correlations with biological character and distinct differences among SRC coactivator family members. Endocrinology 141 3534-3545.

Laws SC, Carey SA, Ferrell JM, Bodman KM \& Cooper RL 2000 Estrogenic activity of octylphenol, nonylphenol, bisphenol A and methoxychlor in rats. Toxicological Sciences 54 154-167. 
Lyttle CR, Damian-Matsumura P, Juui H \& Butt TR 1992 Human estrogen receptor regulation in a yeast model system and studies on receptor agonists and antagonists. Fournal of Steroid Biochemistry and Molecular Biology 42 677-685.

McKenna NJ \& O’Malley BW 2000 From ligand to response: generating diversity in nuclear receptor coregulator function. Journal of Steroid Biochemistry and Molecular Biology 74 351-356.

Margeat E, Poujol N, Boulahtouf A, Chen Y, Müller JD, Gratton E, Cavaillès V \& Royer CA 2001 The human estrogen receptor $\alpha$ dimer binds a single SRC-1 coactivator molecule with an affinity dictated by agonist structure. Fournal of Molecular Biology 306 433-442.

Murdoch FE \& Gorski J 1991 The role of ligand in estrogen receptor regulation of gene expression. Molecular and Cellular Endocrinology 78 C103-C108.

Nikov GN, Hopkins NE, Boue S \& Alworth WL 2000 Interactions of dietary estrogens with human estrogen receptors and the effect on estrogen receptor-estrogen response element complex formation. Environmental Health Perspectives 108 867-872.

Sehested A, Juul A, Andersson AM, Petersen JH, Jensen TK, Müller J \& Skakkerbaek NE 2000 Serum inhibin A and inhibin B in healthy prepubertal, pubertal, and adolescent girls and adult women: relation to age, stage of puberty, menstrual cycle, follicle-stimulating hormone, luteinizing hormone, and estradiol levels. Fournal of Clinical Endocrinology and Metabolism 85 1634-1640.
Sheeler CQ, Dudley MW \& Khan SA 2000 Environmental estrogens induce transcriptionally active estrogen receptor dimers in yeast: activity potentiated by the coactivator RIP140. Environmental Health Perspectives 108 97-103.

Suen C.S, Berodin TJ, Mastroeni R, Cheska BJ, Lyttle CR \& Frail DE 1998 A transcriptional coactivator, steroid receptor coactivator-3, selectively augments steroid receptor transcriptional activity. Fournal of Biological Chemistry 273 27645-27653.

Thénot S, Bonnet S, Boulahtouf A, Margeat E, Royer CA, Borgna J-L \& Cavaillès V 1999 Effect of ligand and DNA binding on the interaction between human transcription intermediary factor $1 \alpha$ and estrogen receptors. Fournal of Molecular Endocrinology 13 2137-2150.

Wang H, Peters FA, Zeng X, Tang M, Ip W \& Khan SA 1995 Yeast two-hybrid system demonstrates that estrogen receptor dimerization is ligand-dependent. Fournal of Biological Chemistry 270 23322-23329.

Webb P, Lopez GN, Greene GL, Baxter JD \& Kushner PJ 1992 The limits of the cellular capacity to mediate an estrogen receptor. Fournal of Molecular Endocrinology 6 157-167.

Received in final form 26 February 2002 Accepted 27 March 2002 


\section{Appendix}

$$
\begin{aligned}
& \frac{\mathrm{d}[\mathrm{R}]}{\mathrm{d} t}=-k 1[\mathrm{R}]\left[\mathrm{E}_{2}\right]+k 2\left[\mathrm{R} \bullet \mathrm{E}_{2}\right]-k 1[\mathrm{R}]\left[\mathrm{E}_{2}\right]+k 2\left[\mathrm{R} \bullet \mathrm{E}_{2}\right] \\
& \frac{\mathrm{d}\left[\mathrm{R} \cdot \mathrm{E}_{2}\right]}{\mathrm{d} t}=k 1[\mathrm{R}]\left[\mathrm{E}_{2}\right]-k 2\left[\mathrm{R} \bullet \mathrm{E}_{2}\right] \\
& \frac{\mathrm{d}\left[\mathrm{E}_{2}\right]}{\mathrm{d} t}=-k 1[\mathrm{R}]\left[\mathrm{E}_{2}\right]+k 2\left[\mathrm{R} \cdot \mathrm{E}_{2}\right] \\
& \frac{\mathrm{d}[\mathrm{X}]}{\mathrm{d} t}=-k 3[\mathrm{R}][\mathrm{X}]+k 4[\mathrm{R} \bullet \mathrm{X}] \\
& \frac{\mathrm{d}[\mathrm{D}]}{\mathrm{d} t}=-k 5\left[\mathrm{R} \bullet \mathrm{E}_{2}\right][\mathrm{D}]+k 6\left[\mathrm{D} \cdot \mathrm{R} \bullet \mathrm{E}_{2}\right]-k 7[\mathrm{R} \bullet \mathrm{X}][\mathrm{D}]+k 8[\mathrm{D} \cdot \mathrm{R} \bullet \mathrm{X}] \\
& \frac{\mathrm{d}\left[\mathrm{D} \bullet \mathrm{R} \cdot \mathrm{E}_{2}\right]}{\mathrm{d} t}=k 5\left[\mathrm{R} \bullet \mathrm{E}_{2}\right][\mathrm{D}]-k 6\left[\mathrm{D} \bullet \mathrm{R} \cdot \mathrm{E}_{2}\right] \\
& \frac{\mathrm{d}[\mathrm{D} \bullet \mathrm{R} \bullet \mathrm{X}]}{\mathrm{d} t}=k 7[\mathrm{R} \bullet \mathrm{X}][\mathrm{D}]-k 8[\mathrm{D} \bullet \mathrm{R} \bullet \mathrm{X}] \\
& \frac{\mathrm{d}[\mathrm{A}]}{\mathrm{d} t}=-k 9\left[\mathrm{D} \cdot \mathrm{R} \bullet \mathrm{E}_{2}\right][\mathrm{A}]+k 10\left[\mathrm{D} \bullet \mathrm{R} \bullet \mathrm{E}_{2} \bullet \mathrm{A}\right]-k 11[\mathrm{D} \bullet \mathrm{R} \bullet \mathrm{X}][\mathrm{A}] \\
& \frac{\mathrm{d}\left[\mathrm{D} \bullet \mathrm{R} \bullet \mathrm{E}_{2} \bullet \mathrm{A}\right]}{\mathrm{d} t}=k 9\left[\mathrm{D} \bullet \mathrm{R} \bullet \mathrm{E}_{2}\right][\mathrm{A}]-k 10\left[\mathrm{D} \bullet \mathrm{R} \bullet \mathrm{E}_{2} \bullet \mathrm{A}\right] \\
& \frac{\mathrm{d}[\mathrm{D} \bullet \mathrm{R} \bullet \mathrm{X} \bullet \mathrm{A}]}{\mathrm{d} t}=k 11[\mathrm{D} \bullet \mathrm{R} \bullet \mathrm{X}][\mathrm{A}]-k 12\left[\mathrm{D} \bullet \mathrm{R} \bullet \mathrm{X}_{2} \bullet \mathrm{A}\right] \\
& \frac{\mathrm{d}\left[\mathrm{D} \bullet \mathrm{R} \bullet \mathrm{E}_{2} \cdot \mathrm{Rp}\right]}{\mathrm{d} t}=k 9\left[\mathrm{D} \cdot \mathrm{R} \bullet \mathrm{E}_{2}\right][\mathrm{Rp}]-k 10\left[\mathrm{D} \bullet \mathrm{R} \cdot \mathrm{E}_{2} \bullet \mathrm{Rp}\right] \\
& \frac{\mathrm{d}[\mathrm{D} \bullet \mathrm{R} \bullet \mathrm{X} \bullet \mathrm{Rp}]}{\mathrm{d} t}=k 11[\mathrm{D} \bullet \mathrm{R} \bullet \mathrm{X}][\mathrm{Rp}]-k 12\left[\mathrm{D} \bullet \mathrm{R} \bullet \mathrm{X}_{2} \bullet \mathrm{Rp}\right] \\
& \frac{\mathrm{d}[\mathrm{Rp}]}{\mathrm{d} t}=-k 9\left[\mathrm{D} \cdot \mathrm{R} \cdot \mathrm{E}_{2}\right][\mathrm{Rp}]+k 10\left[\mathrm{D} \cdot \mathrm{R} \cdot \mathrm{E}_{2} \cdot \mathrm{Rp}\right]
\end{aligned}
$$

